\title{
Ecological-and-Economic Evaluation of Vinyl Chloride Production in Mineral Resource Clusters
}

\author{
Irina Kudryashova ${ }^{1, *}$, Evgeniy Kharlampenkov ${ }^{1}$, Natalia Zakharova $^{2}$, Anastasiya \\ Kolevatova ${ }^{1}$ \\ ${ }^{1}$ Plekhanov Russian University of Economics, Kemerovo branch, 650992, 39, Kuznetskiy prospect, \\ Kemerovo, Russia \\ ${ }^{2}$ Plekhanov Russian University of Economics, 117997, 36, Stremyanny lane, Moscow, Russia
}

\begin{abstract}
Over the past six years, the volume of plastics production in primary forms in Russia increased by $57 \%$, exceeding 7.8 million tons in 2017. During this period, the production capacities were substantially renovated; new plants were put into operation. Increasing the competitiveness of Russian polyvinyl chloride (PVC) is possible on the basis of the integrated use of raw materials, the use of innovative technologies and reduction of production costs. When calculating costs, the following aspects were taken into account: type, availability and cost of raw materials, the number of chemical stages of final product production, its yield, energy intensity and material consumption of the process, the possibility of combining this method of production with other production processes of a chemical company, i.e. complex use of all obtained products. This is due to the low cost of raw materials, the clustering of coal and chemical enterprises and energy companies located in the Kemerovo region, which makes the production of PVC competitive.
\end{abstract}

\section{Introduction}

Polyvinyl chloride (PVC) can really be considered a construction material of the XXI century. Its unique properties are in demand in the production of building structures, pipes, shoes, computer housings and household appliances. The share of PVC in the total consumption of plastics is $18 \%$, which allows it to occupy an honorable third place. According to analysts, the demand for PVC in the world market will grow by an average of $1.4 \%$ per year and by 2020 can reach 43.5 million tons. Global production capacities for PVC have increased by almost $30 \%$ to 55 million tons per year in the period 2007-2017. For the Russian polymer industry, recent years have been marked by a significant breakthrough. All polymers, except for polystyrene plastics, showed a significant increase in production volumes in $2016(19 \%)$. The production of vinyl chloride polymers, including the compositions, reached 0.85 million tons, but the highest share of imports remains in the PVC segment (33\% in 2016 against $47 \%$ in 2011) [1].

\footnotetext{
* Corresponding author: kudrina2007@mail.ru
} 
Despite the positive dynamics, Russia remains a net importer of polymers [1]. The shortage of raw materials has become a serious obstacle to the development of the polymer industry in Russia. The biggest problems arose for the manufacturers of PVC, which were repeatedly forced to stop the existing production or to have it underloaded because of the problems with the supply of ethylene, which is the raw material for the production of vinyl chloride. The growth in capacities for ethylene (and propylene) production is in its turn limited by the availability of the oil and gas raw materials [1]. The problem of increasing the volume of PVC production can be solved by using for the production of vinyl chloride acetylene produced on the basis of carbide technology or obtained from methane extracted from coal seams.

\section{Materials and methods}

Russia is moving to a qualitatively new level of its development. In the face of growing external threats that reduce the international competitiveness of the Russian economy and its regions, the further development of the country through the extraction and sale of natural resources in the external market becomes impossible. In the coming years, Russia will have to create and launch a new mechanism for economic development, based on rational interaction between man and nature, man and technology, also to find its place in the world economy at the current stage of global development. This task is especially important for the coal industry, and it is impossible to solve it without reliance on internal resources, development of internal markets and territories on the basis of innovations.

Russian Federation is the richest country in terms of natural resources and has the largest mineral resource base of fuel and energy resources that can satisfy not only the country's needs, but also the world's needs. According to the statistical survey of world fuel and energy resources prepared by transnational oil and gas corporation BP (Statistical Review of World Energy (June 2017)), in the end of 2016 Russia ranked second in the world in terms of proven natural gas reserves, sixth in terms of proven oil reserves and third in terms of proven coal reserves [2].

The fuel and energy complex of Russia plays a pivotal role in the country's economy. For instance, in 2016, the fuel and energy complex of Russia provided $22.6 \%$ of the country's GDP; $52.6 \%$ of budget revenues received from production, processing and export of its products. $56.9 \%$ in the country's exports [3]. At the same time, Russia's leading positions in the world trade in energy resources affect negatively economic stability of the country in the light of a fall in world energy prices and of anti-Russia sanctions.

Kuzbass, the main coal basin in Russia, is in the most difficult situation. As of 2017, the region produces more than $59 \%$ of the country's coal, accounting for $76 \%$ of all Russian coal exports [4]. These numbers confirm the fact that the region does not create high added value, that high-tech industries are not being developed and that the resource specialization of this region is being consolidated. The export-oriented model of economic development of the Kemerovo region has led to the fact that the region concentrates mainly on the first production stages of the technological chain characterized by such features as high capital intensity, disruption of ecological balance, low demand for research and development, high-performance workforce, disinterest in development of related and auxiliary production processes. This explains the region's unresponsiveness to innovation, the stability of the region's single-industry structure, and difficulties with economic diversification.

Clear signs, that the current model of the coal industry of Kuzbass is uncompetitive, are already to be seen. This entails a crisis of the existing economic paradigm of the Kemerovo region, concentrated on coal [5]. According to the authors, Kuzbass should not abandon coal as a kind of a "pillar" for the regional economy. On the contrary, it is necessary to find such models for the development of the coal industry that will turn it from a "donor" into a 
"driver" for the development of the regional economy and the Kemerovo region as a whole. In this regard, it seems that the solution of these problems can be closely related to the transition from extensive use of natural resources to integrated resource extraction with sustainable socio-economic development of the territory, mutually beneficial partnership of science, authorities and business on the principles of cluster economy.

The authors are convinced that mineral raw materials' clusters will act as a tool for increasing the efficiency of the regional economy, and such a tool should not realize the idea of saving the coal industry, but start a new paradigm of regional development, one of the elements of which may be coal methane, considered as a raw material for obtaining acetylene.

Introduction of coal methane as a full-fledged (along with coal) basic system element of the mineral raw materials' cluster is extremely important. Forecast resource volumes of methane in the main coal basins of Russia are estimated at 83.7 trillion $\mathrm{m}^{3}$, Kuzbass coal basin accounting for 13.1 trillion $\mathrm{m}^{3}$, which makes the Kemerovo region the most promising district for methane extraction and production of acetylene from it [6].

As for the foreign experience in obtaining acetylene, China has succeeded in this matter. Currently, with the help of carbide technology $70-80 \%$ of PVC is produced in China [7]. The return of China to the acetylene process used in the production of VCM (vinyl chloride monomer) was due to the low cost of calcium carbide (despite its high energy intensity), the low price of coal and electricity produced in the North-Western provinces. For the most part, VCM and PVC in China are produced from acetylene, which is extracted from calcium carbide. The acetylene process can be used in Russia, taking into account the quality and the reserves of coking coals [8]. For Kuzbass, the methods of obtaining acetylene both with carbide technology and from methane are quite applicable, taking into account the development of methane extraction technologies from coal seams. This will reduce the cost of production of acetylene.

\section{Results and discussion}

The initial raw material components for the production of acetylene in carbide technology are coal coke with a carbon content of $96-98 \%$ and lime, the raw material for the production of which are limestone, dolomite, chalk and marl. In these rocks, the $\mathrm{CaCO}_{3}$ content should be at least $70 \%$, or about $55 \%$ of $\mathrm{CaO}$ calcite. It is possible to use non-coking coals, but the carbon content in them is $60-70 \%$, therefore, more energy will be needed for production. The raw material for production can be coke produced by PJSC "Koks", and limestone of the Fedorovskoye deposit, located near the river "Poludennyi Shurap", having reserves of category $\mathrm{B}+\mathrm{C} 1818$ thousand $\mathrm{m}^{3}$. The delivery of limestone from other areas of the region is possible. For the production of calcium carbide, relatively cheap coke grades with particles of 6-25 mm can be used. The production of calcium carbide has a shop for the production of quicklime. The main equipment in the production of quicklime is the kiln. In the rotary kiln the firing calcination lasts about 6 hours; in the shaft kiln, calcination takes about 24-36 hours. The choice of production technology and equipment significantly affects the cost of the obtained product. In the production of quicklime for the production of calcium carbide, only pure limestones of a fine-grained, uniformly granular structure are used, in which the $\mathrm{CaCO}_{3}$ content should be higher than $96 \%$. As a basis for estimating the cost of production of calcium carbide and acetylene, the data of West German companies implementing this technology were taken [9].

When choosing production technology, the cost ratio for different types of raw materials in the production of calcium carbide is important for economic evaluation. The share of costs for coke ( $6 \%$ of humidity) in the production of $\mathrm{CaC}_{2}$ is $36 \%$ in total plant costs, for limestone $-6 \%$, for electricity costs - 34\%. Salaries of production and management 
personnel amount to $32-33 \%$ of the cost price of calcium carbide. As can be seen from the numbers above, the most significant item of expenditure is the cost of electricity, because for the production of 1 ton of $\mathrm{CaC}_{2} 3400 \mathrm{kWh}$ of electricity are required, which costs the manufacturer 12580 RUB in a factory of the Kemerovo region (at a price of 3.7 RUB per 1 $\mathrm{kWh}$, as of 2017). The cost of the coke breeze used for the production of calcium carbide as of 2016 is 9277 RUB per ton, which would mean 6960 RUB per ton of the product produced. Taking into account the material balance, the production cost of 1 ton of $\mathrm{CaC}_{2}$ is about 19333 RUB per ton. The market price of a ton of calcium carbide in Russia in 2017 was between 80 and 125 thousand RUB per ton. An important task is to reduce energy intensity and production costs. Traditionally, calcium carbide is produced in ore-thermal furnaces of continuous direct heating. Electricity is supplied to the reaction space of the furnace by means of electrodes, the reaction zone itself is an electrical conductor, the share of the electric arc is meanwhile rather small, and it does not exceed 10-20\% of the full capacity of the furnace [8]. There is a method for producing calcium carbide in a reactor as a result of the synthesis, carried out at a temperature of at least $1700-1800^{\circ}$ by induction heating of the reaction mass in the atmosphere of $\mathrm{CO}_{2}$. The technical solution offered by the authors makes it possible to use coal along with coke in the production process, to increase the yield of the final product and to reduce the energy intensity of the production of calcium carbide [9].

The obtained calcium carbide is a raw material for the production of acetylene, which is obtained by decomposition of calcium carbide with water; the reaction is exothermic with a large release of heat. Calcium carbide makes up to $94 \%$ of the production costs. For the production of 1 ton of acetylene 3.2 tons of calcium carbide are required, while the cost of electricity for 1 ton of acetylene is $100 \mathrm{kWh}$. Taking into account the previously calculated cost price of 1 ton of calcium carbide, the costs will make up 93440 RUB. The price of acetylene will be equal to 65815 RUB per ton. The price of acetylene on the Russian market is about 1700 RUB per kg, i.e. 1700000 RUB per ton.

Analyzing the value of the obtained acetylene as the main component in the production of vinyl chloride using carbide method, which constitutes $42 \%$ of the production costs, one can conclude that the value of vinyl chloride, taking into account the material balance, will not exceed 84.4 thousand RUB per ton. It should be mentioned that in the period between 2014 and 2017 the average export prices of vinyl chloride polymers in primary forms fell by $69.9 \%$, from 211447.7 RUB per ton to 63750.8 RUB per ton. The situation on the market of polyvinyl chloride polymers is determined by Chinese producers that use carbide technology. The cost price of the obtained raw materials is largely dependent on the volume of production. In largescale production (for PVC this is 45000-50000 tons per year) the cost price of raw materials tends to decrease.

The alternative technology for obtaining acetylene is the use of natural gas. This technology is realized in OAO (open joint-stock company) «Novomoskovsk stock company «Azot». Natural gas comprising $98.0 \%$ of methane, about $1 \%$ of other hydrocarbons and $1 \%$ of $\mathrm{N}_{2}$ and $\mathrm{O}_{2}$ is used as a raw material. The content of acetylene obtained in the production process is of $98.5 \%$ on average. This allows the enterprise to produce vinyl chloride of high quality that is processed into polyvinyl chloride of two types, C-7058M and E-6250\%. The use of acetylene technology sets a task for the enterprise to reduce energy intensity of production, which will ensure the competitiveness of the final products.

For Kuzbass the source of raw materials for the acetylene production can be methane extracted from coal seams. Methane production from coal seams in 2017 amounted to about 14 million $\mathrm{Nm}^{3}$ or 10035 tons per year. It is planned that by 2040 the volume of gas production reaches 1.67 billion $\mathrm{m}^{3}$ per year or 1197 thousand tons per year. Moreover, nowadays liquefied natural gas plants are being built and put into operation. 
In the chemical industry raw materials are the most cost-intensive parameter. Analysis of gas extracted from coal seams has shown that it is quite complex; concentration of methane $\left(\mathrm{CH}_{4}\right)$ is $90 \%$, ethane $\left(\mathrm{C}_{2} \mathrm{H}_{6}\right)-5 \%$, propane $\left(\mathrm{C}_{3} \mathrm{H}_{8}\right)$ is $2 \%$, the degree of methane conversion is $91 \%$. Analysis of literature sources has shown that the production of acetylene from methane or natural gas may use two main technologies: thermo-oxidative pyrolysis and electrocracking [10]. The technology of oxidative pyrolysis is simpler, well explored by industry, but the use of this technology requires the oxygen supply. «Novomoskovsk stock company «Azot» uses this technology, since this enterprise includes air separation shop that utilizes nitrogen as a raw material in its primary production, whereas oxygen is a by-product. But construction of the air separation shop that ensures the production needs of only one product is, in our opinion, an ineffective investment. When using this technology, the yield of acetylene is $13 \%$. The electrocracking technology does not require the use of oxygen, but to achieve higher efficiency hydrogen is introduced in the methane mixture in the ratio of $1: 2$. This increases the acetylene yield to $50 \%$.

The production of 1 ton of acetylene theoretically requires 2 tons of methane, but in practice 3 tons of methane, equivalent of $4200 \mathrm{Nm} 3$, which is $15120 \mathrm{RUB}$ as of 2018 . Electrocracking process is energy intensive, the cost is about $10000-13000 \mathrm{kWh}$ per 1 ton of acetylene or about 48100 RUB as of 2017. Analysis of the cost structure of the acetylene production from methane has led us to conclude that raw material and electricity costs account together for $70 \%$ of the total production costs; cost of production of 1 ton of acetylene from methane using electrocracking is going to be about 90 thousand RUB per ton. The use of the electric arc process developed by DuPont (USA) in the production of acetylene from methane could reduce the cost of electricity to $6500 \mathrm{kWh}$ per ton. In this case, the cost of acetylene would be 56 thousand RUB per ton, which is comparable to the cost of acetylene produced using the carbide method. A number of researchers believe that if we consider the cost of production of one ton of acetylene using carbide method $100 \%$, in the case of thermo-oxidative pyrolysis of methane it would constitute $40 \%$, for electrocracking of methane it is reduced to $30-35 \%$ of the cost of carbide method [11]. A polyvinyl chloride manufacturing facility would have to address the issue of transporting raw materials (methane) using either pipeline transport if the main production site is located near the extraction site, or delivery of liquefied or compressed methane with gas transportation vehicles, for example, with РРСТ-48 (ППЦТ-48), receiving raw materials from liquefied natural gas (LNG) production plants. LNG delivered to the plant is pumped into storage tanks, what should increase the turnover of gas carriers.

It is possible to implement a combined acetylene production process based on the use of coal developed by Huls (Germany) and AVCO (USA). In this technology, the hydrogenplasma process on coal raw materials is realized. This process assumes injection of coal dust into the hydrogen plasma stream. Depending on the coal type, the yield of acetylene in the implementation of this technology can reach $35 \%$, but the purification processes are complicated due to heteroatomic additives. The use of this technology allows reducing the cost of the obtained acetylene by $15-20 \%$ in comparison to the carbide method [11].

Vinyl chloride $\left(\mathrm{CH}_{2}=\mathrm{CHCl}\right)$ is produced from acetylene by hydrochlorination. The process is carried out in the gas and liquid phases in a tubular type apparatus. For gas-phase hydrochlorination, dry $97-99 \%$ acetylene and highly concentrated hydrogen chloride are used in the molar ratio $1: 1$. The process is conducted in the presence of a catalyst - mercuric chloride $\left(\mathrm{HgCl}_{2}\right)$, which is prepared by impregnating activated carbon with an aqueous solution of mercuric chloride, followed by drying. The mixture of hydrogen chloride acetylene is passed through the reaction space filled with a solid catalyst. The starting materials should be dry so that no acetaldehyde or excessive corrosion of the equipment occur [12]. 
Reaction products are a gaseous mixture containing 93\% of vinyl chloride and other impurities that require cleaning. The method of catalytic hydrochlorination of acetylene is currently quite widespread only in China due to the rich coal reserves, availability of cheap hydropower, but it can be used in Kuzbass enterprises.

One ton of vinyl chloride requires $0.42-0.45$ tons of acetylene, acetylene costs amount to 25200 RUB per ton of vinyl chloride, the cost of hydrogen chloride at a flow rate of 0.670 tons per 1 ton of vinyl chloride would be 28500 RUB per ton of vinyl chloride. The cost of electricity is 450 RUB per ton of the final product. Considering that expenses on the basic raw materials and energy make up $75 \%$ of total production costs, the cost price of 1 ton of vinyl chloride obtained from acetylene by hydrochlorination can mount to about 72 thousand RUB. Vinyl chloride for obtaining polyvinyl chloride should contain at least $99.9 \%$ of the monomer and the minimum amount of impurities. Pure vinyl chloride should be stored in steel tanks at temperatures between $-50{ }^{\circ} \mathrm{C}$ and $-30{ }^{\circ} \mathrm{C}$ under nitrogen in the absence of inhibitors.

Enterprises for the production of PVC operate in a volatile market. This is seen by the decrease of the cost of 1 ton of PVC from 84 thousand RUB to 62-68 thousand RUB in 2017. In the first place, it is associated with the use of innovative technologies in the acetylene production and with the use of cheap raw materials.

The choice of the technological process for the production of acetylene largely depends on both the costs of the main production and the costs of auxiliary production. This, in turn, forms a chain of added value, making the product competitive or partially competitive under favorable market conditions for final goods and raw materials. In our opinion, the use of acetylene production technology from methane or coal by electrocracking or pyrolysis in a stream of low-temperature plasma is more appropriate, since it reduces the cost of producing limestone and oxygen, necessary for oxidative pyrolysis, which reduces the cost price of the product. Methane conversion reaches then $94-99 \%$, and the yield of acetylene is $65.6 \%$, whereas energy costs $-7000-9000 \mathrm{kWh}$ per ton of the product.

\section{Conclusions}

Summing up the above, it can be argued that the research and development of modern technological solutions in mineral raw materials' clusters contribute to the increase the added value in the mining (in this case - coal) industry by involving related industries. It seems that it is the relationship between the resource industries and other industries of the economy that can solve the problem of transition to a qualitatively new level of development. Resource industries will begin to form demand for innovations, service, engineering, financial, transport and other services, stimulate the development of domestic (including regional) market.

The use of mineral raw materials' clusters of innovative technologies in practice can help to follow the intensive way of field development, reducing the "technological" losses of extracted raw materials, and to have a positive impact on the economy of extracting enterprises, which will open up new opportunities for the formation of global value chains using the available results of intellectual activity, while allowing one to significantly extend the part of the chain accounting for the Russian market, as well as to ensure sustainable development of the region's economy on the principles of rational subsoil use.

Increasing the production of PVC to cover the needs of the domestic market and exports is a major task, given that the demand for PVC on the global market will grow by $1.4 \%$ per year on average and by 2020 may reach 43.5 million tons. In Russia, there is a steady trend of growing production of vinyl chloride polymers. One of the directions of increasing the volume of production, taking into account raw materials and energy resources, is the production of PVC mineral raw materials' clusters based on the use of coal and methane 
extracted from coal seams. The production of a competitive product is ensured by the use of innovative technologies for the production of acetylene from cheap raw materials, such as methane, by means of electric cracking or from coal in a stream of low-temperature plasma. The analysis of production costs carried out in the article made it possible to assert sufficient competitiveness of PVC production on the basis of acetylene processing obtained from coal and methane extracted from coal seams. Synchronization of the development targets in the polymer industry with plastics processing industry (plans to introduce new capacities, indicators of availability and supply of polymer raw materials, as well as prospective tasks for expanding exports of final products) will allow to create prerequisites for the growth of market demand for polymers and switch to "non-raw" economic development.

This approach is in line with the objectives of the state "Strategy for the development of the chemical and petrochemical complex for the period up to 2030", the main goal of which is the transition from the development model based on the export of raw materials to the one based on innovation and investment by increasing the depth of processing.

\section{References}

1. A.V. Volkov, Huge Polymers Market (HSE, Moscow, 2016)

2. BP Statistical Review of World Energy (BP Press, London, 2017)

3. The share of the mineral sector in GDP (Rosstat, Moscow, 2017)

4. A.V. Kapitskaya, I.N. Paskar, Economics and Innovation Management, 1, 39-44 (2017) DOI: 10.26730/2587-5574-2017-1-39-44

5. Yu. A. Fridman, G. N. Rechko, E. U. Loginova, E. V. Alekseenko, D. V. Kritskiy, ECO, 9, 110-122 (2015)

6. M. Tyulenev, S. Zhironkin, E. Tyuleneva, A. Abay, S. Anyona, M. Hellmer, Coal Int., 265:3, 30-34 (2017)

7. M. Goel, M. Sudhakar, Carbon utilization: applications for the energy industry (New York, Springer, 2017)

8. I. A. Kudryashova, N. V. Zakharova, E. I. Kharlampenkov, E3S Web Conf., 21, 02016 (2017)

9. M. Biron, Industrial applications of renewable Plastics: Environmental, Technological and Economic advances (London, William Andrew Publishing, 2016)

10. A. I. Pushkarev, Ai-Min Zhu, Xiao-Song Li, R. V. Sazonov, High Energy Chemistry, 43:3, 202-208 (2009)

11. G. G. Garifzyanova High Energy Chemistry, 51:11, 98-100 (2008) 